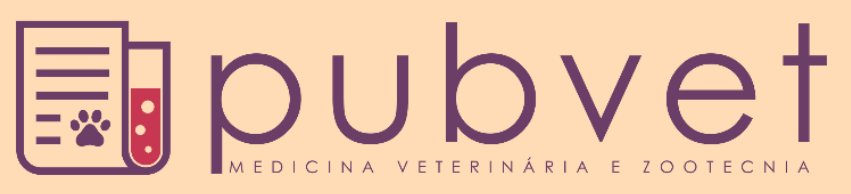

https://doi.org/10.31533/pubvet.v13n7a378.1-8

\title{
A arte como instrumento de ensino de bem-estar animal
}

\author{
João Paulo Novelletto Pisa ${ }^{1 *}$, Jorge Luiz Conte Tacito², Denise Pereira Leme ${ }^{3 \bullet}$ \\ ${ }^{I}$ Discente do Programa de Pós-Graduação em Agroecossistemas da Universidade Federal de Santa Catarina e Núcleo de Equideocultura \\ e Bem-Estar de Equinos (NEBEq-LETA-UFSC), Departamento de Zootecnia e Desenvolvimento Rural, Florianópolis -SC Brasil. \\ ${ }^{2}$ Médico Veterinário Autônomo e NEBEq-LETA-UFSC, Departamento de Zootecnia e Desenvolvimento Rural. Florianópolis-SC Brasil. \\ ${ }^{3}$ Professora da Universidade Federal de Santa Catarina e NEBEq-LETA-UFSC, Departamento de Zootecnia e \\ Desenvolvimento Rural. Florianópolis -SC Brasil. \\ *Autor para correspondência, E-mail: joaopisamdv@gmail.com
}

Resumo. Arte é um modo de compreender a vida e o mundo e se manifestar sobre eles. Os animais foram essenciais para a construção da civilização da espécie humana, nada mais legítimo deles estarem em manifestações artísticas e culturais humanas. Porém, as artes também podem estar presentes na educação. Segundo as diretrizes para os currículos dos cursos de medicina veterinária e de zootecnia, há necessidade de fazer com que os graduandos valorizem a dimensões éticas e humanísticas, considerando aspectos sociais e culturais, com consciência da realidade e da sua importância para a sociedade. A nossa proposta neste artigo é discutir em forma de revisão de literatura sobre o uso de diferentes formas de artes, para que sejam apresentadas em sala de aula, como assuntos aos quais elas se referem. Desta forma, que as artes propiciem diálogos e manifestações individuais acerca do papel do conhecimento científico em argumentações sobre as artes que tem como foco o animal ou a relação humano-animal. Neste artigo serão considerados para discussão os livros: O Gaúcho, de José de Alencar (1870); Doctor Dolittle, de Hugh Lofting (1920), Vidas Secas, de Gracialiano Ramos (1938), a séries Heartland (CBC, 2007-presente); as músicas Poncho Molhado, de José Claúdio Machado e Atirei o Pau no Gato (tradicional e nova- Domínio Público) e os filmes Rio 2 (20 Century FOX, 2014) e Touro Ferdinando (20 Century FOX, 2016). A partir de tais discussões, pode-se estimular a reflexão sobre ser um animal, a relação humano-animal e suas consequências para os animais por meio diferentes formas de artes aqui apresentadas, extrapolando para as mais diversas formas de expressão cultural, como poemas, poesias, pinturas e esculturas.

Palavras-chaves: Educação, ética, filmes, músicas, zooliteratura

\section{The arts as an instrument of teaching of animal welfare}

Abstract. Art is a way of understanding life and the world and manifesting about them, animals were essential to the construction of the civilization of the human species, nothing more just that they be in human artistic and cultural manifestations. According to the guidelines for the curricula of veterinary medicine courses, there is a need to make the graduates have more human and social skills, with awareness of the reality and its importance for society. The proposal would then be to use various forms of arts to discuss in the form of literature review in the classroom the subjects they bring up, so as to foster dialogue and individual opinions and scientific knowledge. In this article will be seen books: Vidas Secas (Gracialiano Ramos, 1938) and Gaúcho de José de Alencar (1870); the Heartland series (CBC, 2007-present); the songs Poncho Molhado (José Claudio Machado) and Atirei o Pau no Gato (traditional and new- Public Domain) and the films of Rio 2 (20o Century FOX, 2014) and Touro Ferdinando (20o Century FOX, 2016). It can be suggested 
that through the arts one can reflect the animal, the human-animal relationship and its consequences.

Keywords: Education, ethics, movies, music, zooliterature

\section{El arte como instrumento de enseñanza de bienestar animal}

Resumen. El arte es una forma de entender la vida y el mundo y manifestarse sobre ellos, los animales fueron esenciales para la construcción de la civilización de la especie humana, nada más que estar en manifestaciones artísticas y culturales humanas. De acuerdo con las directrices para los planes de estudio de los cursos de medicina veterinaria y zootecnia, es necesario que los graduandos valoricen dimensiones éticas y humanísticas, considerando aspectos sociales y culturales, con conciencia de la realidad y su importancia para la sociedad. La propuesta es discutir en forma de revisión de literatura sobre la utilización de diversas formas de artes, para ser presentadas en la clase como temas a los cuales estas se refieren, a fin de fomentar el diálogo y las opiniones individuales y el conocimiento científico. En este artículo consideraremos para discusión los libros: O Gaúcho de José de Alencar (1870); Doctor Dolittle, de Hugh Lofting (1920); Vidas Secas (Gracialiano Ramos, 1938); la serie Heartland (CBC, 2007-presente); las canciones Poncho Molhado (José Claudio Machado) y Atirei o Pau no Gato (dominio público tradicional y nuevo) y las películas de Rio 2 (20 Century FOX, 2014) y Touro Ferdinando (20o Century FOX, 2016). Se puede sugerir que a través de las artes se puede reflejar el animal, la relación humanoanimal y sus consecuencias.

Palabras clave: Educación, ética, películas, música, zooliterature

\section{Introdução}

A arte é um modo de compreender a vida e o mundo e se manifestar sobre eles; ela tem como objetivo contar histórias, provocar o pensamento, criticar a sociedade, representar a realidade, educar ou ainda exibir a manifestação dos sentimentos e emoções de quem a produz (Bozzano et al., 2013). Os animais são essenciais para a construção da civilização da espécie humana seja por questões de alimento, vestuário, transporte, lazer e companhia, entre outras funções (Fraser \& Broom, 1997).

O ensino de Bem-estar Animal está presente nos cursos de Medicina Veterinária e Zootecnia, pois faz parte da formação destes profissionais, além de estimular a pesquisa e uma relação humano-animal pautado na ética; porém, ainda é uma disciplina recém-inserida nos cursos (Molento, 2005). Em um estudo sobre grades curriculares de cursos de medicina veterinária no Brasil (2016), foi visto que 38,0\% não possuíam disciplinas sobre ética e bem-estar animal, 46,3\% tinham a disciplina de Bem-estar animal e $8,2 \%$ de bioética (Uliana et al., 2018). O conceito de bem-estar animal é definido como uma tentativa do indivíduo de se adaptar ao momento em que ele vive (Koknaroglu \& Akunal, 2013; Molento, 2005). Atualmente discute-se sobre o tema "bem-estar único" ou "uma só saúde", que alia o bem-estar dos animais com o dos seres humanos e questões de conservação ambiental, tendo-se o contexto total como foco (Pinillos et al., 2016).

Desta forma, o objetivo deste estudo é mostrar como as artes podem ser utilizadas para o ensino de Bem-estar Animal, seguindo as orientações contidas nas diretrizes curriculares do MEC aliado ao conceito de "um bem-estar, uma saúde, um ambiente", para formar profissionais capacitados e críticos que atuem de forma a elevar a qualidade do serviço prestado à sociedade.

\section{Metodologia}

Segundo as diretrizes para os currículos dos cursos de medicina veterinária e zootecnia (MEC, 2003, 2006, respectivamente), há necessidade de fazer com que os graduandos tenham mais habilidades humanas e sociais, com consciência da realidade e da sua importância para a sociedade; assim, não apenas deve-se formar um profissional que saiba realizar as práticas inerentes de sua profissão, mas também que seja uma pessoa cidadã e que contribua de forma geral para a sociedade. Propostas alinhadas a esta puderam ser vistas nos trabalhos de Luna \& Tadich (2019) e Fleith (2019). As primeiras 
colocaram a necessidade de um aprendizado sobre bem-estar equino com uma visão mais regional, além de global, para que as necessidades de cada realidade fossem atendidas, já a segunda realizou uma pesquisa sobre a criatividade na pós-graduação e entre pesquisadores, tendo a conclusão que estes grupos veem a necessidade de aumentar a produção de modo mais criativo; porém, verificaram que há limitações institucionais e pessoais para que isto ocorra, mencionando que trabalhos em conjunto, de forma mais interdisciplinar e com diferentes modos de ensinar podem contribuir para um pensamento mais criativo dos profissionais. Por estes motivos apresentados, pode-se considerar o uso das artes para promover uma educação voltada ao bem-estar único, a partir do pensamento crítico e com referências às múltiplas realidades que existem, já que estes também são os objetivos das artes em si. Um exemplo prático do uso da arte na educação foi o descrito por Arruda (2017) que realizou um trabalho com crianças e adolescentes de 10 a 15 anos em uma escola rural, em Cachoeira Grande, sobre zooliteratura no gênero de fábula. Foi um trabalho muito importante para o bem-estar animal, pois os alunos daquele local tinham uma boa relação apenas com os equinos e caninos; porém, mais distante de suínos, aves, gatos, silvestres e outros, que eram ignorados ou estavam sob uma perspectiva negativa. Assim, este projeto ajudou na conscientização e reflexão crítica sobre o modo que eles lidavam com outros animais, além dos mais próximos, como passo inicial para mudanças de atitude.

As artes podem ser um modo de facilitar a metodologia ativa, em que o objetivo é o discente ser mais ativo na busca do saber e o docente e os livros são personagens que servem para a mediação (Oliveira \& Faria, 2019). Em uma pesquisa recente realizada em instituições de ensino de cursos de graduação de Medicina Veterinária do estado de Minas Gerais, foi visto que 23 de 28 docentes utilizam esta metodologia em sala de aula, pelos meios de tempestade cerebral, estudo de caso, dinâmicas, dramatização, juris e entre outros, também foi visto que tantos os professores como estudantes concordam que ela ajuda no processo de aprendizagem (Meirelles et al., 2019).

A proposta deste estudo é apresentar e discutir em forma de revisão de literatura algumas formas de artes, que podem ser usadas em sala de aula como auxílio na prática de metodologias ativas, sobre os assuntos e contextos que elas trazem à tona, de forma que propicie o diálogo e expressão de opiniões individuais aliados à busca e ao confronto do conhecimento científico com o exposto pela determinada forma de arte. Para este estudo, selecionamos as seguintes obras: O Gaúcho, de José de Alencar (1870); Doctor Dolittle, de Hugh Lofting (1920), Vidas Secas, de Gracialiano Ramos (1938), a séries Heartland (CBC, 2007-presente); as músicas Poncho Molhado de José Claúdio Machado e Atirei o Pau no Gato (tradicional e nova - Domínio Público) e os filmes Rio 2 (20 Century FOX, 2014) e Touro Ferdinando $\left(20^{\circ}\right.$ Century FOX, 2016). Cada forma de arte conta uma história, tem um contexto social, cultural e econômico da vida humana e do animal, já que os animais convivem com os humanos, ambos os grupos com seus respectivos sentimentos e emoções expressos ou descritos. Assim, estimular-se-á as questões sobre "um bem-estar, uma saúde, um ambiente" em cada obra citada, pois isto faz parte da utilidade de usar artes para a educação e na construção do pensamento.

\section{Livros}

Zooliteratura é um termo que se refere ao estudo e aos textos que abrangem as diferentes formas da relação humano-animal presentes em obras literárias. Este novo campo da ciência literária também pode ser chamado de "estudos animais". A zooliteratura tem como características a interdisciplinaridade e a dialética das áreas de ciências humanas e naturais. Seu principal objetivo é fazer refletir sobre o "outro", humano ou animal (real ou fictício), o antropomorfismo animal, a animalidade humana e as todas as suas inter-relações (Guida, 2011; Junqueira, 2013; Maciel, 2007).

Num ambiente sulista, encontramos "O Gaúcho" de José de Alencar, publicado em 1870 e disponível no site domínio público, que se passa no bioma pampa. Neste livro se tem a visão da relação humanoequino, a construção do afeto do personagem principal Manuel Canho, o comportamento dos cavalos, as formas de doma e o pensamento do bem-estar animal. Este livro está relacionado à cultura gaúcha; portanto, traz um aspecto regionalista do Brasil, o que possibilita o aprendizado estimulado pela inserção na cultura regional de alguns discentes e os atrair para os temas propostos, motivando discussões sob diferentes pontos de vista ético e culturais, ao mesmo tempo em que deve estimular empatia e respeito ao outro, humano ou não humano. Neste caso, o pensar sobre a relação e o afeto com os equinos ou outros animais a partir de "O Gaúcho" pode servir de tema de trabalho, independente da região brasileira, 
onde os alunos podem criar suas próprias histórias inspiradas em suas relações e afetos com os animais com os quais já se relacionaram, o que os fará valorizar a vida e provocará o pensamento de como cada um lida com os animais.

Para outra região do Brasil, na caatinga, encontramos "Vidas Secas" (1938) de Graciliano Ramos, que nos traz a personagem animal Baleia, uma cadela considerada membro de uma família de retirantes nordestinos que tentam sobreviver à seca. Um capítulo importe para nosso assunto é o nono, que tem como título a Baleia, pois relata a eutanásia, uma situação que atinge muitos profissionais da clínica de pequenos animais. Fabiano pensa que a cadela está com raiva, então decide matá-la, para evitar seu sofrimento e eliminar o risco de contaminação da sua família, mostra a situação de luto da família e mais adiante alguns momentos de arrependimento. Além dela, o livro tem outros personagens animais, como o papagaio que serviu como alimento para a família, vacas minguando à sede e uma égua domada de forma bruta, como um simbolismo cultural. Com esta obra, pode-se construir o conhecimento das emoções e sentimentos dos animais e a visão cultural que cada um possui sobre as diferentes relações humano-animal. Ainda, inserir a questão clínica da doença da Baleia, pois são descrito os sinais apresentados pela personagem e a sintomatologia apresentada na obra indica o estado de saúde da cadela, dada as condições ambientais e direcionar para os diagnósticos diferenciais de prováveis doenças, discorrer sobre a opção da eutanásia e do luto subsequente, num contexto sem a presença do profissional médico veterinário. Entretanto, apesar de naquele contexto social; obviamente que não haveria um médico veterinário, pode-se estimular o pensamento sobre tantas realidades que evidenciam a relação humano-animal, e esta sim deve ser pensada pelos médicos veterinários e zootecnistas em todos os contextos possíveis.

Outro livro que pode ser usado para aulas de medicina veterinária é o Fabuloso Dr. Pacífico, mais popularmente conhecido como o Doctor Dolittle, escrito por Hugh Lofting em 1920 (Lofting, 1975). A obra conta a história de um médico que aprende a conversar com os animais e por causa disso se torna médico de animais, por ter mais habilidade de entender o que o animal passa e dar a ele um tratamento mais adequado. $\mathrm{O}$ médico aprendeu a falar com os animais com ajuda de um papagaio, que o explicou que os animais falam com os humanos por meio de seus corpos e expressões. Recentemente, tem-se utilizado as expressões faciais e vocalizações dos animais como indicadores de emoções e status de bem-estar animal (Descovich et al., 2017; Lansade et al., 2018; Stomp et al., 2018) ou simplesmente para saber que cabras preferem pessoas com expressões faciais positivas (Nawroth et al., 2018) e que equinos também usam a expressão facial e os sons emitidos pelos humanos para o reconhecimento de emoções (Nakamura et al., 2018). Um trecho que destacamos é quando o médico avalia um cavalo com problemas de visão e o animal reclama que o veterinário tratou dele para outra doença, justamente por não saber reconhecer o que o paciente equino dizia com seu corpo, como protesto o cavalo deu um coice naquele que considerou abusado por não ter indicado seu tratamento adequado.

\section{Série}

A história gira em torno da personagem Amy, órfã que "herdou" da mãe o dom de intuir sobre as necessidades dos cavalos. Ela vive em um rancho da família, onde também trabalha principalmente com distúrbios comportamentais dos equinos. Amy trata os cavalos pelo uso das técnicas de horsemenship, ao mesmo tempo em que lida com a complexidade do ser humano e seus problemas, para assim ajudar a recuperar os animais. Além disso, o namorado e futuro marido de Amy, ingressa na Universidade para o curso de Medicina Veterinária e começa a auxiliar o veterinário que presta serviços em Heartland. Outro aspecto abordado em Heartland é o uso de terapias não convencionais. Com esta obra de ficção pode-se apresentar aspectos sobre da saúde mental dos animais e como os problemas humanos afetam os animais, os desafios da graduação e o uso de terapias não convencionais e as competências do médico veterinário em nosso país e como elas têm sido discutidas em outros países (Ramey, 2011), incluindo nesta discussão o tema "One Health" (Salmanov et al., 2018) e "One Walfare" (Pinillos et al., 2016), em português, os termos já utilizados "Uma Só Saúde" e "Bem-Estar Único", respectivamente.

\section{Músicas}

A música infantil "Atirei o Pau no Gato" evidencia o pensamento sobre a violência para com os gatos e o contraponto para esta música resultou na recente versão "Não Atire o Pau no Gato". Esta última 
versão tem sido usada nas escolas de educação infantil, o que mostra uma transformação na sociedade, que passa a ser crítica com relação à violência contra animais, portanto a nova versão da música vem refletir melhor a relação do humano com o gato que a versão original. Veja a comparação das versões original e modificada no Quadro 1.

Quadro 1. Comparativo das letras da música infantil "Atirei o Pau no Gato" e "Não Atire o Pau no Gato", original e modificada, respectivamente

\begin{tabular}{|ll|}
\hline Original & Modificada \\
\hline Atirei o pau no gato tô tô & Não atire o pau no gato (to-to) \\
Mas o gato tô tô & Porque isso (Isso-Isso) \\
Não morreu reu reu & Não se faz (faz-faz) \\
Dona Chica cá & O gatinho (nho-nho) \\
Admirou-se se & É nosso amigo (go-go) \\
Do berro, do berro que o gato deu: & Não devemos maltratar \\
Miau! & Os Animais \\
& Miau! \\
\hline
\end{tabular}

Fonte: https://www.letras.mus.br/cantigas-populares/983981/ https://www.letras.mus.br/cantigas-populares/870902/

Outra música que pode ser usada como ferramenta de ensino para futuros médicos veterinários e zootecnistas é Poncho Molhado, da cultura gaúcha, cantada por diversos artistas como José Claudio Machado. Ela conta basicamente sobre uma pessoa que leva uma tropa de bovinos para o abate e se sente triste por isto. Letra:

"Poncho molhado, o olhar na tropa

E no horizonte

Vai o tropeiro, devagar, estrada a fora

A chuva encharca, está chovendo desde ontonte

Dói dentro d'alma, esta demora

Irmão do gado, ele se sente nesta hora

E o seu destino, também vai, neste reponte

Igual a tropa, neste tranco, estrada a fora

Sempre encharcado de horizonte

A tropa segue, devagar, mugindo tonta

Talvez pressinta que seu fim

É o matadouro

E o tropeiro, entristecido, se dá conta

O boi é bicho, mais tem alma sob o couro

O boi é bicho, mais tem alma sob o couro..."

Fonte: https://www.letras.mus.br/jose-claudio-machado/876236/

Nota-se que o personagem coloca que o animal é dotado de emoções e sentimentos, inclusive dotado de alma, sente a tristeza de fazer isto com os animais, até sente-se irmão dos animais; porém, ele continua fazendo seu trabalho. São duas coisas que podemos aprender com esta música. Em primeiro, o conceito de esquizofrenia moral idealizado pelo filósofo Gary Francine, que tem como definição este paradoxo, que mesmo os humanos considerando os animais como seres sencientes e capazes de sentir emoções, continuam a usá-los, pois os animais são considerados como propriedades do ser humano (Rouanet \& Carvalho, 2016). O segundo conceito a discutir é o da dissonância cognitiva, um termo da psicologia que explica o sentimento do personagem da música, pois ela tem como definição a sensação de quando uma pessoa passa por uma situação na qual enfrenta suas convicções e, a partir deste sentimento, a pessoa pode mudar o que faz, ou continua fazendo ou ao menos inventa uma desculpa para continuar suas atitudes (Martins, 2015). No caso, considerar as capacidades dos animais perceberem o futuro próximo, em vista de suas mortes, para o sustento humano, tem a reação do personagem em continuar a fazer seu trabalho. Com esta canção, há possibilidade de refletir sobre nossas ações para com os animais, independente da nossa cultura e realidade, e nossas opiniões sobre estas atitudes. 


\section{Animações do cinema}

As duas animações que discutiremos têm como similaridade tratarem sobre os temas animalidade e devir-animal, que são temas comumente vistos em estudos sobre zooliteratura. A animalidade seria o ser animal, mas, o ser animal deve ser pensado pelo devir-animal, que também pode ser definido pelas mudanças e interpretações ás quais submetemos os animais de acordo com a nossa percepção, seja pelo processo de domesticação ou pela interpretação da natureza animal feita pelo ser humano. Na vida, sabese que muitos animais tiveram sua natureza modificada pelo ser humano conforme a necessidade do humano, não a deles; com isto, houve consequências para a saúde mental e comportamental dos animais, sejam aqueles de companhia, produção de alimentos, esportes, lazer ou de qualquer utilidade, isto é um resultado constantemente reforçado ou modificado pela forma como o humano sente e interage com o animal. Os animais que hoje vivem próximos ao humano vieram de ancestrais livres na natureza, até que o ser humano modificou suas vidas, pela própria interpretação. Todavia, mesmo considerando o devir-animal, os animais não perderam suas origens comportamentais, mas as direcionaram de forma patológica, sendo isto, portanto, usado como indicativo de qualidade de manejo e bem-estar animal (Broom, 1991; Guida, 2011).

A animação que exemplifica algumas questões de animais de produção é o Touro Ferdinando $\left(20^{\text {th }}\right.$ Century Fox, 2017). Mesmo que a finalidade "tourada" seja inicialmente diferente da produção de alimento, é uma visão do ser humano sobre a animalidade. No início do filme, é mostrada a infância do personagem e as etapas pelas quais ele deve passar para aprender a ser um touro de tourada. Enquanto seus amigos ficavam competindo entre si, ele preferia cuidar de flores, mostrando um temperamento mais pacífico, pois repudiava violência mesmo em meio à convivência com o "sonho de todos os touros" que era ser "o escolhido" para a tourada. Os tourinhos viviam em baias individuais, longe dos adultos e em certo momento, o pai de Ferdinando foi escolhido, mas nunca mais voltou, levando Ferdinando a viver um luto. Ferdinando aproveitou uma oportunidade para fugir e viver com uma família, onde foi amado e tratado como membro. Diferente da realidade que vivia; porém, ainda um devir, desta vez em harmonia com a personalidade dele. Deixou de ser um bezerro comum, mas em vez de se tornar um touro de tourada, passou a agir como um animal de estimação; inclusive o personagem canino da trama tem uma fala muito interessante: "Cachorros são cachorros, galinhas são galinhas e touros são touros". Por provocar uma confusão na cidade, Ferdinando foi obrigado a voltar para o local de onde fugiu, mas então já adulto, retomou a saga da escolha para ser um touro de tourado ou o abate. Outra situação abordada no filme, de forma antropomórfica, é que os animais que não eram capazes de serem bons para o objetivo, iam para o abate, tendo assim, a função mais conhecida para os bovinos, que é a produção de carne, mas problematizada como se fossem seres humanos "imprestáveis" (Broom, 1991; Broom \& Molento, 2004), neste momento do filme a questão abate pode ser bem discutida, inserindo questões de abate humanitário.

A animação RIO 2 (20 ${ }^{\text {th }}$ Century Fox, 2014), feita pelo brasileiro Carlos Saldanha, tem o Brasil como cenário. Blu é uma arara-azul humanizada, com uma família humana e animal, e que não conhece a vida na floresta. A família humana do Blu vai para a Amazônia, a companheira Jade (tema do primeiro filme RIO) também quer ir, para que seus filhos conheçam a vida na natureza. Eles vão, com outras aves, lá se deparam com um santuário de araras-azuis, quando eles pensavam serem os últimos da espécie. Neste local, Jade reencontrou sua família biológica, os filhos se adaptaram; porém, Blu sofreu, por não saber ser uma arara-azul, além de a protagonista causar confusões por não se comportar como um animal típico da espécie. Jade quer ficar, mas Blu não, então ele vai ao encontro da sua família humana quando vê a selva sendo desmatada. É um filme que caracteriza bem a questão do devir-animal e o devirhumano, ao redor do personagem Blu. No filme ele se destaca por ter um comportamento diferente, mais urbano, porém na realidade, uma das principais consequências disso pode ser a ocorrência de automutilação, apresentada pelos psitaciformes (araras como o Blu). Esta alteração de comportamento pode ser causada por infecção, problemas de nutrição ou de parasitos, mas o componente mental é o principal, seja pelo ambiente ou isolamento social (Almeida et al., 2008).

\section{Teatro}

Uma clássica peça teatral brasileira é o Pagador de Promessas de Dias Gomes (Gomes, 2002) que estreou em 1960 e foi produzida em filme em 1962, ganhando o prêmio Palma de Ouro, em Cannes. A 
peça conta a trajetória do Zé-do-Burro, um homem humilde que fez uma promessa à Santa Barbara para salvar a vida de seu burro, que havia sido atingido por um raio. Com a cura do animal atribuída à santa, ele leva uma cruz nas costas até uma igreja com nome de Santa Bárbara, no dia de seu festejo. Seu objetivo era colocar a cruz dentro da igreja, mas foi proibido pelo padre que achou que ele era do diabo por ele ter feito a promessa para Iansan e pela promessa ter sido para ajudar a vida de um animal. Ao longo da peça, se discute a dinâmica da sociedade ao redor da religião e do animal, mas para graduandos de veterinária e zootecnia, pode-se também incluir a reflexão sobre o valor da vida do animal para seu tutor.

\section{Conclusão}

Pelas artes apresentadas neste artigo pode-se refletir o animal, a relação humano-animal e suas consequências, além de ter uma ideia de diversas realidades geográficas e sociais, sendo assim, alinhado com os conceitos de One Healh e One Walfare e com as diretrizes propostas pelo Conselho Nacional de Educação para o curso de veterinária e zootecnia, e também alinhadas as metodologias ativas, formando assim profissionais mais humanos e capacitados para a vida no mercado de trabalho. Espera-se que também, seja estimulada a leitura de livros de literatura, assim como mais consumo de artes, com uma visão mais profunda e crítica entre os profissionais de veterinária e zootecnia.

\section{Agradecimentos:}

O presente trabalho foi realizado com apoio da Coordenação de Aperfeiçoamento de Pessoal de Nível Superior -Brasil (CAPES) - Código de Financiamento 001.

\section{Referências bibliográficas}

Almeida, M. V., Souza, M. G., Bassan, L. M., Queiroz, F. \& Pereira, R. E. P. (2008). Automutilação em aves silvestres-revisão de literatura. Revista Científica Eletrônica de Medicina Veterinária(11):1-5.

Arruda, K. B. (2017). A fábula na sala de aula: a gênese, o gênero e a zooliteratura. Paper presented at the IV Congresso Nacional de Educação, João Pessoa, Paraíba.

Bozzano, H., Frenda, P. \& Gusmão, T. C. (2013). Arte em Interação. São Paulo, Brasil: Gma Editora Ltda.

Broom, D. M. (1991). Animal welfare: concepts and measurement. Journal of Animal Science, 69(10):4167-4175.

Broom, D. M. \& Molento, C. F. M. (2004). Animal welfare: concept and related issues-review. Archives of Veterinary Science, 9(2):1-11.

Descovich, K., Wathan, J. W., Leach, M. C., Buchanan-Smith, H. M., Flecknell, P., Farningham, D. \& Vick, S.-J. (2017). Facial expression: An under-utilized tool for the assessment of welfare in mammals. ALTEX: Alternatives to Animal Experimentation, 34(3):409-429.

Educação, Ministério da. Resolução CNE/CES 1, de 18 de fevereiro de 2003. MEC, Brasília, 2003.

Educação, Ministério da. Resolução No 4, de 2 de fevereiro de 2006. MEC, Brasilia, 2006.

Fleith, D. d. S. (2019). The role of creativity in graduate education according to students and professors. Estudos de Psicologia, 361-10.

Fraser, A. F. \& Broom, D. M. (1997). Farm animal behaviour and welfare. Cambridge: Cab International.

Gomes, D. (2002). O Pagador de Promessas. Rio de Janeiro, Brasil: Ediouro Publicações S/A.

Guida, A. M. (2011). Literatura e estudos animais. Raído, 5(10):287-296.

Junqueira, M. A. (2013). O animal escrito-um olhar sobre a zooliteratura contemporânea. Revista do Programa de Estudos Pós-Graduados em Literatura e Crítica Literária, 11301-306.

Koknaroglu, H. \& Akunal, T. (2013). Animal welfare: An animal science approach. Meat Science, 95(4):821-827. doi: http://dx.doi.org/10.1016/j.meatsci.2013.04.030 
Lansade, L., Nowak, R., Lainé, A.-L., Leterrier, C., Bonneau, C., Parias, C. \& Bertin, A. (2018). Facial expression and oxytocin as possible markers of positive emotions in horses. Scientific Reports, $8(1): 1-11$.

Lofting, H. (1975). O fabuloso Dr. Pacífico. Rio de Janeiro, Brasil: Tecnoprint.

Luna, D. \& Tadich, T. A. (2019). Why Should Human-Animal Interactions Be Included in Research of Working Equids' Welfare? Animals, 9(42):1-15.

Maciel, M. E. (2007). Zoopoéticas contemporâneas. Remate de Males, 27(2):197-206.

Martins, R. P. (2015). Ciência e a dissonância cognitiva. Revista da Clínica Ortodontia Dental Press, 14(4):5-6.

Meirelles, D. V., Cobucci, G. C. \& Cunha, A. F. (2019). Como os docentes e discentes de medicina veterinária avaliam o uso de metodologias ativas na Gradução? Revista CFMV, 8047-58.

Molento, C. F. M. (2005). Bem-estar e produção animal: Aspectos econômicos - Revisão. Archives of Veterinary Science, 10(1):1-11.

Nakamura, K., Takimoto-Inose, A. \& Hasegawa, T. (2018). Cross-modal perception of human emotion in domestic horses (Equus caballus). Scientific Reports, 8(1):1-9.

Nawroth, C., Albuquerque, N., Savalli, C., Single, M.-S. \& McElligott, A. G. (2018). Goats prefer positive human emotional facial expressions. Royal Society Open Science, 5(8):1-8.

Oliveira, G. D. \& Faria, V. P. (2019). Metodologia ativa na educação em medicina veterinária. PUBVET, 13(5):1-7.

Pinillos, R. G., Appleby, M. C., Manteca, X., Scott-Park, F., Smith, C. \& Velarde, A. (2016). One welfare-a platform for improving human and animal welfare. Veterinary Record, 179(16):412-413.

Ramey, D. W. (2011). Alternative Medicine and Equine Welfare - Challenging the Science. In C. Wayne \& B. E. Rollin (Eds.), Equine Welfare (pp. 205-225). USA: Blackwell Publishing Ltd.

Rouanet, L. P. \& Carvalho, M. C. (2016). Ética e direito dos animais. Florianópolis, Santa Catarina, Brasil: Universidade Federal de Santa Maria.

Salmanov, A. G., Kotsyumbas, I. Y. A. \& Trokhymchuk, V. V. (2018). One World - One Health. International Journal of Antibiotics and Probiotics, 2(1):8-17. doi: http://dx.doi.org/10.31405/ijap.21.18.01.

Stomp, M., Leroux, M., Cellier, M., Henry, S., Lemasson, A. \& Hausberger, M. (2018). An unexpected acoustic indicator of positive emotions in horses. PloS One, 13(7):1-23.

Uliana, D., Carvalho, D. \& Bonamigo, E. (2018). Bioética e bem-estar animal nos cursos de medicina veterinária brasileiros. Revista Brasileira de Bioética, 141-16.

Recebido: 26 de junho, 2019.

Aprovado: 25 de julho, 2019.

Publicado: 12 de agosto, 2019.

Licenciamento: Este artigo é publicado na modalidade Acesso Aberto sob a licença Creative Commons Atribuição 4.0 (CC-BY 4.0), a qual permite uso irrestrito, distribuição, reprodução em qualquer meio, desde que o autor e a fonte sejam devidamente creditados. 